\title{
Intra-aortic chord: A new entity?
}

Rachid Zegdi, MD, PhD, ${ }^{\mathrm{a}, \mathrm{b}}$ Arshid Azarine, MD, MSc, ${ }^{\mathrm{c}}$ and Jean-Marc Alsac, MD, $\mathrm{PhD}^{\mathrm{d}, \mathrm{e}}$

From the ${ }^{\mathrm{a}}$ Paris XII University, Paris, France; ${ }^{\mathrm{b}}$ Department of Cardiovascular Surgery, Henri Mondor Hospital, Créteil, France; ${ }^{\mathrm{c}}$ Department of Radiology, Saint Joseph Hospital, Paris, France; ${ }^{\mathrm{d}}$ René Descartes University, Paris, France; and ${ }^{\mathrm{e} D e p a r t m e n t}$ of Cardiovascular Surgery, Georges Pompidou European Hospital, Paris, France.

Disclosures: Authors have nothing to disclose with regard to commercial support.

Received for publication Sept 21, 2017; revisions received Jan 11, 2018; accepted for publication Feb 4, 2018; available ahead of print May 17, 2016.

Address for reprints: Rachid Zegdi, MD, PhD, Department of Cardiovascular Surgery, Henri Mondor Hospital, 51 Ave du Maréchal de Lattre de Tassigny, 94010 Créteil, France (E-mail: rzegdi@ hotmail.com).

J Thorac Cardiovasc Surg 2018;156:355-6

$0022-5223 / \$ 36.00$

Copyright (C 2018 by The American Association for Thoracic Surgery

https://doi.org/10.1016/j.jtcvs.2018.02.003

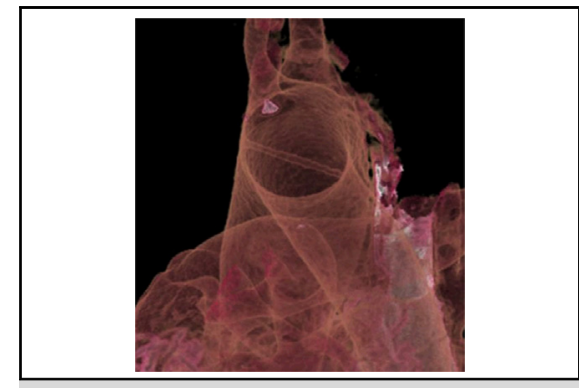

Volume-rendered 3D image showing a chord inside the distal part of the ascending aorta.

\section{Central Message}

Intra-aortic chord is an exceptional entity that is easily recognized on imaging studies of the aorta. It looks like a small, short, plain cylindric tube crossing the aortic lumen.

See Editorial Commentary page 357.

65-year-old woman with hypertension was admitted to the hospital for acute and prolonged anterior chest pain. Clinical evaluation yielded normal results. Transthoracic echocardiography revealed the presence of an apparent
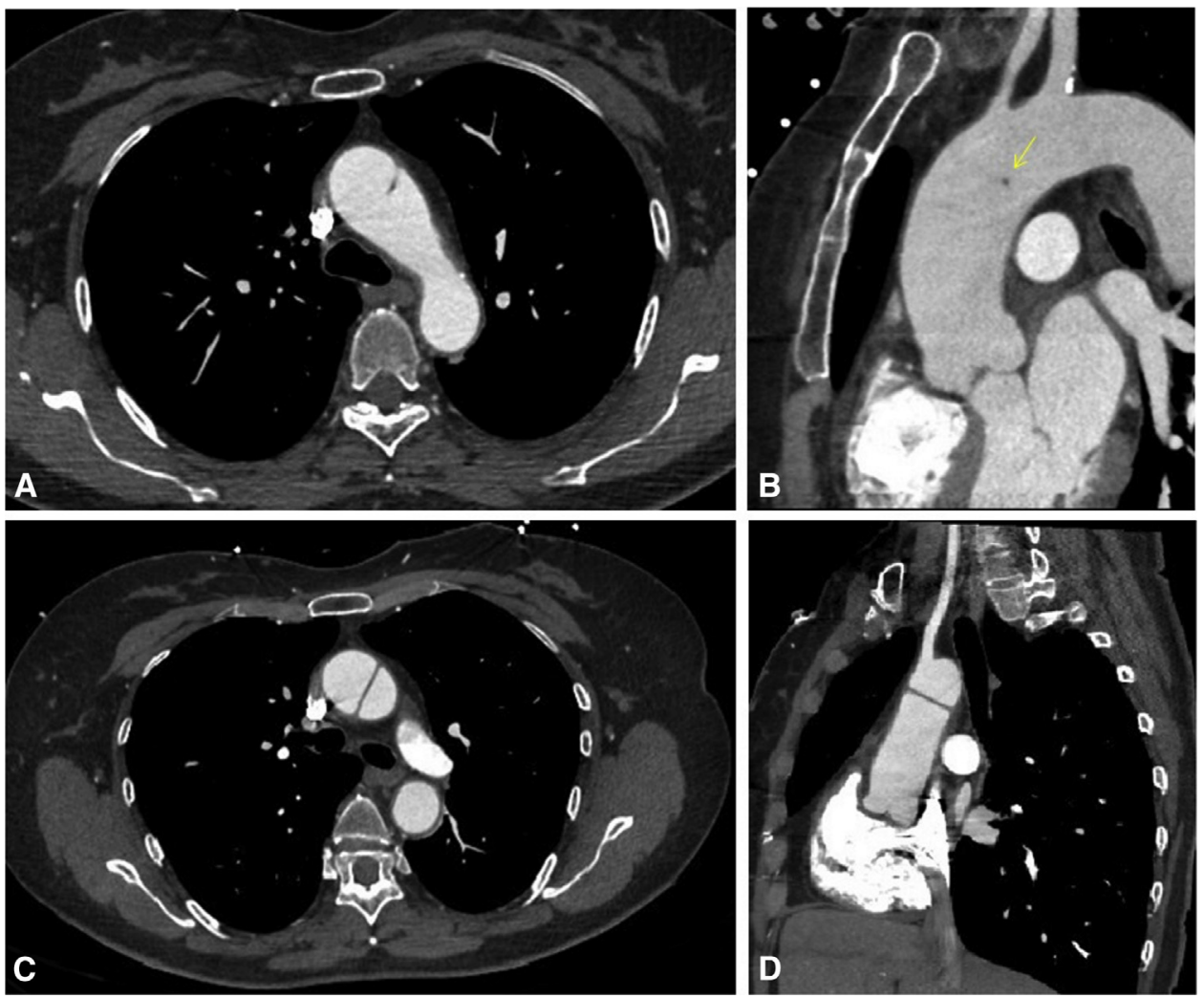

FIGURE 1. A, Multidetector computed tomographic angiography axial slice shows an intimal flap in the distal part of the ascending aorta. B and D, Axial slice (B) and sagittal multiplanar (D) views of the ascending aorta show an intraluminal chord crossing the aorta wall to wall B, C and D, Axial (C) and sagittal (B,D) multiplanar views of the ascending aorta show an intraluminal chord crossing the aorta wall to wall (arrow). 

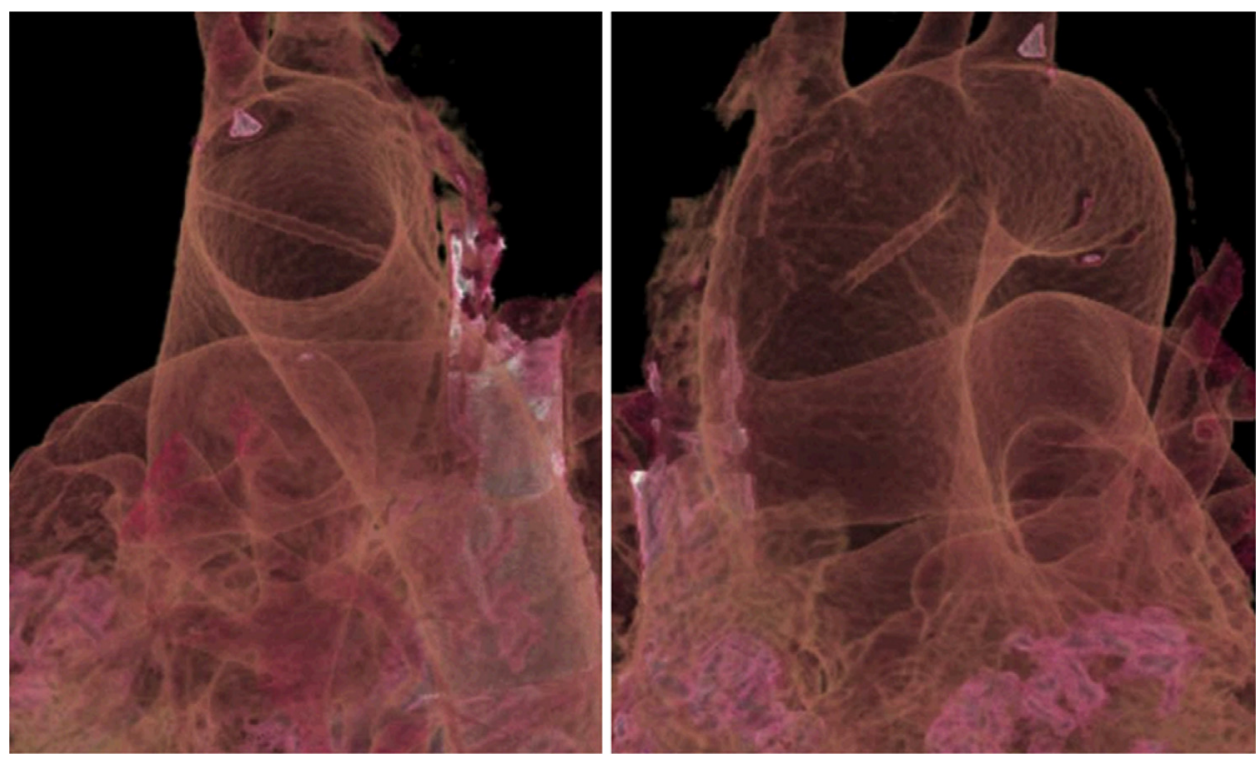

FIGURE 2. Volume-rendered 3-dimensional postprocessed images showing the intra-aortic chord inside the distal part of the ascending aorta.

intimal flap, located at the distal part of the ascending aorta. Multidetector computed tomographic angiography (MDCTA) showed the presence of a linear, 1- to 2-mm thick flap crossing the aorta wall to wall (Figure 1).

Because the MDCTA images were not typical of acute aortic syndrome, the patient's condition was medically managed. The diagnosis of acute aortic syndrome was definitely affirmed rejected with MDCTA performed at day 5;

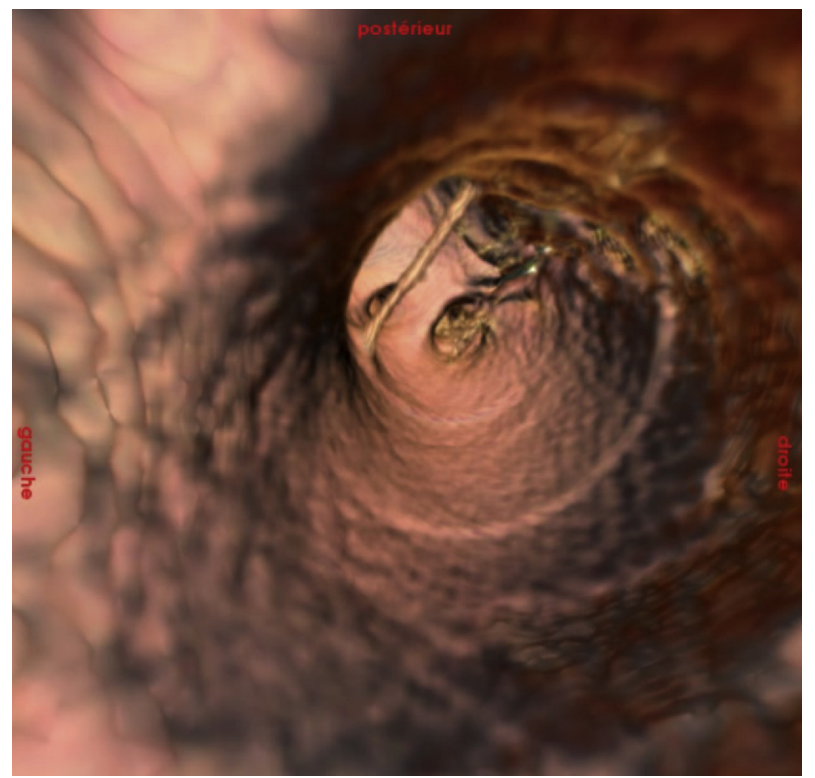

VIDEO 1. Virtual angioscopy of the thoracic aorta. Multidetector computed tomographic angiography volume-rendered images of the thoracic aorta produced with the EndoSize software (Therenva SAS, Rennes, France) show the intra-aortic chord at the distal part of the ascending aorta. Video available at: https://www.jtcvs.org/article/S0022-5223(18)30339-8/fulltext. no aortic hematoma, aortic dissection, or penetrating ulcer was found. Multiplanar 3-dimensional reconstructions of the aorta clearly demonstrated that the apparent intimal flap was rather an atypical retractile chord crossing the lumen of the distal part of the ascending aorta, from one point to another (Figure 2), as also shown by virtual angioscopy (Video 1).

MDCTA is a key examination in the workup of patients with chest pain not related to coronary artery disease. ${ }^{1,2}$ Acute aortic syndrome is usually easily diagnosed. In the case described here, the apparent intimal flap seen on transthoracic echocardiography and initial MDCTA was rather intriguing. It was not associated with the presence of a false lumen, nor with an aortic wall thickening. Its location was restricted to the distal part of the ascending aorta, with no mobility (there was no fluttering of the flap within the aortic lumen), and the lesion was very focal. There were thus many arguments against aortic dissection.

To the best of our knowledge, the description of an intraaortic chord has not been reported so far. This exceptional entity can be accurately assessed by MDCTA of the aorta as a thin linear and short cylindric plain tube, attached to 2 distinct points of the aortic wall and crossing the aortic lumen.

\section{References}

1. Erbel R, Aboyans V, Boileau C, Bossone E, Bartolomeo RD, Eggebrecht H, et al; ESC Committee for Practice Guidelines. 2014 ESC guidelines on the diagnosis and treatment of aortic diseases: document covering acute and chronic aortic diseases of the thoracic and abdominal aorta of the adult. The task force for the diagnosis and treatment of aortic diseases of the european Society of Cardiology (ESC). Eur Heart J. 2014;35:2873-926. Erratum in: Eur Heart J. 2015;36:2779

2. Chin AS, Fleischmann D. State-of-the-art computed tomography angiography of acute aortic syndrome. Semin Ultrasound CT MR. 2012;33:222-34. 